\title{
An Assessment of Human-Livestock Predators Conflict in Central and Eastern Part of Bale Mountains National Park, Ethiopia
}

Israel Sebsibe Tafesse ( $\square$ israelmaru4@gmail.com )

Salale University

Research article

Keywords: Bale Mountains National Park, predators, livestock predation

Posted Date: December 15th, 2020

DOl: https://doi.org/10.21203/rs.3.rs-126640/v1

License: (c) (i) This work is licensed under a Creative Commons Attribution 4.0 International License.

Read Full License 


\section{Abstract}

Background: sharing of space by humans and wildlife at a time may ignite clear conflict. Populations of many species are declined due to the degradation of wildlife habitats caused by agricultural activities. Additionally, livestock may compete with wild herbivores for grazing and reduce the abundance of wild prey for carnivores. A reduction in populations of prey species of large predators might cause carnivores to be attracted towards livestock, ultimately provoke and aggravating the human-carnivores conflict. This study investigated the current status of human-predators conflict in and around the Bale Mountains National Park.

Results: most (72.75\%) respondents agreed on the presence of livestock predation. Major reported predators were spotted hyena (Crocuta crocuta), olive baboon (Papio anubis), African wolf (Canis lupaster), aardvark (Orycteropus afer), genet (Genetta genetta), Ethiopian wolf (Canis simensis), lion (Panthera leo), and leopard (Panthera pardus). Cattle (54.19\%), sheep (70.96\%), goat (32.0\%), donkey $(37.72 \%)$ and horse $(27.54 \%)$ were mentioned as major target of predators. Within the past ten years 1623 sheep, 741 cattle, 639 goats, 193 donkeys, and 124 horses were predated. This study found an increasing trend of livestock predation. The trend was reported to be high within the Park (68\%). During the past ten years, households reported killings of 3320 livestock that cost 347,460.53 USD. Loss of 8.66 USD per month constituted $27.45 \%$ of their monthly income which is expected to have a great sustenance impact. Human settlement (41\%), agricultural practices (38.6\%), overgrazing (25.3\%), deforestation for charcoal production (25.1\%), deliberate fire to free lands for agriculture (17.3\%) were noticed as major causes of livestock depredation.

Conclusions: the results of the present study show that there is strong human-livestock predator conflict in the study area. Therefore, the author suggested that conflict mitigation efforts focus on securing the livestock enclosure to protected areas and regular compensation fees for farmers that face great damage from wildlife. The foremost action should be awareness creation about the environmental, social, and economic importance of protected areas. Park management is also expected to promote community involvements in the future plan of mitigation strategies and practices.

\section{Introduction}

People together with their livestock survive in and around many protected areas in African. Due to plenty of natural resources, rural people are always attracted to the abode of many wildlife species. Sharing of habitats by humans and wildlife at a time may ignite clear conflict and one causes an adverse impact upon the other [6]. For instance, various activities on natural habitats may exacerbate human-wildlife conflict by inducing habitat fragmentation through which living space for wildlife gets diminished [37, 42]. Human-wildlife conflict occurs in different forms all over the world. One of the major forms of conflict between local people and wildlife is livestock predation [3]. Interactions between several carnivore species and domestic animals have been very complex for a long period of time [9]. Predators are rarely a threat 
to humans in Africa, but they are a significant source of livestock losses to both commercial and subsistence livestock producers [11].

Carnivores including lions, leopards, cheetahs, spotted hyenas, wild dogs, and crocodiles, are frequently noticed as main predators causing a great threat to livestock and responsible for the majority of humanwildlife conflicts. This can impose important economic costs to local communities $[41,46]$ and the subsequent elimination of predators through retaliatory action is one of the most omnipresent problems faced by carnivores. This is probably due to local people's view of these large carnivores as government properties and they always want to take their own measures against them to express their opposition [18].

Populations of many species are declined due to the degradation of wildlife habitats caused by agricultural activities [38, 39]. Additionally, livestock may compete with wild herbivores for grazing and reduce the abundance of wild prey for carnivores [47]. A reduction in populations of prey species of large predators might cause carnivores to be attracted towards livestock, ultimately provoke and aggravating the human-carnivores conflict.

Adverse interactions between humans and carnivores have led to severe results including the extinction to some animal species. According to [20], there is a positive relationship between historical patterns of large carnivore extinction probability and human population density. For example, conflict with people over sheep depredation led to the extinction of two carnivorous mammals, the thylacine or marsupial wolf (Thylacinus cynocephalus) in 1930 [47]. Also, the conflict between Ethiopian wolves and pastoralists in different parts of the country has put the species into an endangered state [8].

In the Bale Mountains National Park, different predators are residing, however, they face a problem of human-wildlife conflict as the local people have a tradition of livestock rearing [36]. Livestock production is the best income finding way for many people living in and around the Park. Thousands of people are living inside and very close to the Park boundary. Due to the lack of natural prey in the park (needs investigation), predators are turning to livestock to survive. In return pastoralists eventually kill animals without knowing their importance and current status. Retaliation measures taken by pastoralists put very important endemic species including Ethiopian wolf (Canis simesis) in an endangered state [8].

Therefore, the present study aims to investigate the human-predators conflict in and around the Bale Mountains National Park. Many investigations have been conducted in and around the BMNP for many years. Due to its enormously wide catchment area which covers 247,000 hectares of land with an altitudinal range from 1500 to $4377 \mathrm{~m}$ a.s.I, there is a great need for investigation and assessments to find out the overall effect of human and wildlife conflict [10]. Selected sites of the present study have never been assessed to find livestock depredation extent except for Rira. In this study, major conflict causing predators and root causes of livestock depredation were clearly identified. The economic loss of livestock depredation of the past decade was also analyzed. Local people's attitude towards conflict and their mitigation strategies was also assessed. 


\section{Methods}

\section{Study area description}

Bale Mountains National Park is situated at Bale zone in the Oromia Regional State of Ethiopia. The Park is located within geographical coordinates of $6^{\circ} 29^{\prime} \mathrm{N}-7^{\circ} 10^{\prime} \mathrm{N}$ and $39^{\circ} 28^{\prime} \mathrm{E}-39^{\circ} 57^{\prime} \mathrm{E}$ (Fig. 1), about $400 \mathrm{~km}$ from the capital city of the country. The landscape of the Park is highly varied in size and ranged from $1500 \mathrm{~m}$ a.s.l. to $4377 \mathrm{~m}$ a.s.I. [48]. Different elevation levels consisted within the boundary of the Park determine the temperature, humidity, and rainfall amount and frequency in the area $[5,49]$. According to [14], topographical features within the Park can be divided into three categories based upon elevation levels, the northern slopes between 3000 and $3800 \mathrm{~m}$ a.s.l. comprised of woodlands, grasslands, and wetlands; the central plateau and peaks from 3800- $4377 \mathrm{~m}$ a.s.l. (Tullu Dimtu) including the second highest mountain point of the country with a central afro-alpine plateau. The southern escarpment of moist tropical forest from 1400-3000 m a.s.l. becomes the third topographical category.

Comprising the largest area of Afroalpine habitat on the continent and the second largest moist tropical forest in Ethiopia, it harbors few and rare endemic species of the world [44]. Approximately $26 \%$ of Ethiopian endemic faunal community of the Park consists Ethiopian wolf (Canis simensis), Mountain Nyala (Tragelaphus buxtoni), Menelik's bushbuck (Tragelaphus scriptus meneliki), Serval (Felis serva), Bohor reed buck (Redunca redunca), Giant mole rat (Tachyoryctes macrocephalus), Colobus monkeys (Colobus guereza) and many carnivores $[1,2,26]$.

\section{Sampling Design and Data Collection2}

\section{Preliminary survey}

A preliminary survey was conducted between December 2018 and February 2019 and information was also gathered about the rough extent of human-predators conflict regarding local people's perspective. Based on the information gathered during the preliminary study 31 people were interviewed to check the suitability and comprehensibility of the questionnaire according to the local language of the study area.

\section{Data collection methods}

Data were collected from six kebeles (administrative sub-units) from December 2019 to May 2020, using a questionnaire survey of sample households, key informant interviews, and field observations. Household questionnaires contained both open and close-ended questions. Questionnaire used was adopted from literature $[23,45]$ and modified for the purpose of the study (see Additional file A). Questions concerning every numerical information, general socio-economic status of the community, personal profile, and trend of livestock damage were structured. Open-ended questions that concern their attitude toward wildlife conservation, predators' damage controlling methods, causes of human-predators conflict, and their feedback on the problem were semi-structured. Interviewees were selected based on their age, duration of abidance in the study area, and mainly their position in the community [22]. Key informants were interviewed with some open-ended questions which were designed to gather information 
about local people's reactions to livestock predation, how they used and were benefited from resources within the Park, and their coexistence with wildlife. Data were presented narratively and compared with individuals' responses to the questionnaire. Ten years' retrospective data of livestock damage was collected from sample households and district offices to analyze the monetary loss of households. Photographic field observation (see additional file B) was done to as a complementary method [24].

\section{Sample size and sampling technique}

In the study sites a total of 334 households were chosen based on the sample size determination formula of Cochran [7] as follows.

$$
\mathrm{n}=\left(\frac{\mathrm{n}_{\mathrm{o}}}{1+\mathrm{n}_{\mathrm{o}} / \mathrm{N}}\right),
$$

where $n=$ corrected sample size; $n_{0}=$ required return sample size (based on Cochran's formula $=384$, where margin of error is 0.05 ); $\mathrm{N}=$ total population ( 2575 households from six Kebeles).

Stratified sampling was adopted to pick sampling unites. The study sites were purposively selected based on distance from the Park as to inside the Park (one site), less than $1 \mathrm{~km}$ (two sites), from 1-5 km, and greater than $5 \mathrm{~km}$ (three sites). Households were selected randomly from each kebele. Respondents from each household were randomly selected for interview on a first-come, first-served basis. Respondents were randomly selected with some alteration of sex [32]. All interviews of 334 household were conducted by 12 data collectors with the aid of field assistants who were selected from the community based on their experience of abode in the study sites. Participant members of the community and their local leaders were informed about the aim of the study and asked for proceeding permission [25] and verbal consent was obtained from all respondents.

\section{Data Analysis}

Data were analyzed using descriptive statistics and responses were compared with the chi-square test. A correlation was also done to determine the relationship between livestock damage and distance from the Park.

\section{Results}

\section{Location and grazing land ownership of the respondents}

A greater proportion of respondents lived outside the Park boundary (83.8\%). From the remaining proportion, $4.93 \%$ of respondents live within the Park, $4.07 \%$ live near to the Park up to $1 \mathrm{~km}$, and $7.2 \%$ live near to the Park up to $5 \mathrm{~km}$. Most of the respondents (56.59\%) had their own private grazing land. The mean size of private grazing land in study sites was $1.15 \pm 0.1$ ha per household. There was a strong positive correlation between distance from the Park and the private grazing land ownership $(r=0.93, P<$ 0.05). 


\section{Livestock predation}

Most (72.75\%) respondents agreed on the presence of livestock predation. Many respondents (82.9\%) of Rira (within the Park) and $82.5 \%$ of Welti Tosha (WT - within $1 \mathrm{~km}$ distance) were faced a greater proportion of livestock predation. The Problem caused by predators was also significantly differed across the study sites $\left(X^{2}=16.06, P<0.05\right)$. The degree of the conflict was reported to be more extensive within $1 \mathrm{~km}$ and $5 \mathrm{~km}$ distance from the Park than within the Park $(r=0.76, P<0.05)$.

Eight livestock predators were reported in the study area. These predators were spotted hyena (Crocuta crocuta), olive baboon (Papio anubis), African wolf (Canis lupaster), aardvark (Orycteropus afer), genet (Genetta genetta), Ethiopian wolf (Canis simensis), lion (Panthera leo), and leopard (Panthera pardus). Kebeles were differed in the number of reported predators $\left(F_{5328}=3.82, P<0.05\right)$. All predators were mentioned by respondents of Rira live inside the Park $(P<0.05)$. Tierce $(33 \%)$ of the respondents reported olive baboons and spotted hyenas as major predators of their livestock. About $28 \%$ of respondents reported African wolves with olive baboons and spotted hyenas. Many who blamed African wolf were from and Rira (58.5\%) which took $4.5 \%$ proportion of all respondents. Some (11.4\%) of the respondents blamed aardvark and genet for chicken depredation. Very small (3.3\%) respondents, exclusively from FA (1 kilometer distance from the Park) of and Rira (Within the Park) mentioned Ethiopian wolf. A few people reported that some of livestock were injured and killed by lions (0.9\%) and leopards (1.5\%).

\section{Table 1 Major livestock predators in and around BMNP (\%)}

\begin{tabular}{|c|c|c|c|c|c|c|c|}
\hline Predators & AT & WT & FA & WA & IS & Rira & Total \\
\hline Spotted hyena & 2.69 & 3.89 & 2.99 & 0.9 & 3.3 & 0 & 13.77 \\
\hline Olive baboon & 2.4 & 2.99 & 1.8 & 1.8 & 1.2 & 0 & 10.19 \\
\hline African wolf & 0 & 0 & 0 & 0 & 0 & 4.5 & 4.5 \\
\hline Spotted hyena and olive baboon & 14.37 & 6.59 & 4.5 & 7.19 & 0.3 & 0 & 32.95 \\
\hline $\begin{array}{l}\text { Spotted hyena, olive baboon and African } \\
\text { wolf }\end{array}$ & 6.29 & 5.09 & 3 & 4.79 & 5.99 & 2.7 & 27.86 \\
\hline Aardvark and genet & 5.09 & 2.99 & 0 & 2.1 & 1.2 & 0 & 11.38 \\
\hline Ethiopian wolf & 0 & 0 & 1.5 & 0 & 0 & 1.8 & 3.3 \\
\hline Lion & 0 & 0 & 0 & 0 & 0 & 0.9 & 0.9 \\
\hline Leopard & 0 & 0 & 0 & 0 & 0 & 1.5 & 1.5 \\
\hline No predation & 4.49 & 3.59 & 3.89 & 4.49 & 8.38 & 2.1 & 26.95 \\
\hline
\end{tabular}


There was no correlation between livestock predation and distance from the Park $(r=0.26, P>0.05)$. This analysis showed that reported predators do not attack livestock because local people are lived in or near the Park. Respondents who faced more livestock predation had negative attitude towards predators $(\mathrm{r}=$ $-0.58, \mathrm{P}<0.05)$. And respondents who faced a few livestock predation events had a positive attitude towards wildlife $(r=6.18, P<0.05)$.

Cattle (54.19\%), sheep (70.96\%), goat (32.0\%), donkey (37.72\%) and horse $(27.54 \%)$ were mentioned as major target of predators. Many respondents live near to the Park (74.6\%), far from the Park $(61.05 \%)$, within the Park (80.5\%) reported sheep depredation. Cattle depredation report was provided by $18.3 \%$ of respondents. A great proportion of goat depredation was in Rira (73.2\%) and FA (52.3\%). All the rest of kebeles' response of goat depredation was under $35 \%$. Much of the pack animals were predated from (51\%) far from the Park and the least (19\%) from within the Park (Table 2).

Table 2 Percentage of livestock predation during the past ten years in the study area (\%)

\begin{tabular}{|lllllll|}
\hline \multicolumn{7}{c|}{ Depredated livestock } \\
\hline Kebeles & $\mathrm{n}$ & Cattle (\%) & Sheep (\%) & Goat (\%) & Donkey (\%) & Horse (\%) \\
\hline AT & 80 & 18.26 & 19.5 & 1.8 & 10.2 & 6.28 \\
\hline WT & 57 & 9.28 & 12.3 & 5.39 & 8.68 & 4.79 \\
\hline FA & 44 & 6.28 & 9.28 & 6.89 & 5.09 & 4.79 \\
\hline WA & 48 & 9.58 & 9.88 & 4.19 & 6.59 & 5.68 \\
\hline IS & 64 & 6.58 & 10.2 & 4.79 & 3.59 & 4.49 \\
\hline Rira & 41 & 4.19 & 9.88 & 8.98 & 3.59 & 1.49 \\
\hline total & 334 & 54.19 & 70.96 & 32.0 & 37.72 & 27.54 \\
\hline
\end{tabular}

The majority (98.26\%) of cattle was depredated by spotted hyenas in the byre at night time and the rest were killed by lion in Rira. Hyenas were reported to attack cattle whether they were in the byre or outside. But the lion did not break byre. Rather it focuses on cattle that stay outside the byre at the night. Many sheep (59.8\%) and goats ( $65.8 \%$ ) were killed by olive baboon while $27.9 \%$ sheep and $29.2 \%$ of goats were killed by African wolves and $7.9 \%$ sheep by spotted hyenas. The Ethiopian wolf was also reported to kill lamb (1.2\%) and goats (2.6\%) within $1 \mathrm{~km}$ distance from the Park and within the Park. Ethiopian wolf did not dare to kill adult sheep. In addition to the Ethiopian wolf (Table 3), there was another predator for sheep and goats, the, which was responsible for the loss of sheep (3.15\%) and goats (2.4\%).

Table 3 Percentage of predators responsible for each species of livestock (\%) 


\begin{tabular}{|llllll|}
\hline Predators & Cattle & Sheep & Goat & Donkey & Horse \\
\hline Olive baboon & 0 & 59.82 & 65.8 & 0 & 0 \\
\hline Spotted hyena & 98.26 & 7.85 & 0 & 98.44 & 100 \\
\hline African wolf & 0 & 27.97 & 29.1 & 0 & 0 \\
\hline Ethiopian wolf & 0 & 1.19 & 2.58 & 0 & 0 \\
\hline Lion & 1.73 & 0 & 0 & 1.55 & 0 \\
\hline Leopard & 0 & 3.5 & 2.43 & 0 & 0 \\
\hline
\end{tabular}

\section{Trend of livestock predation}

All kinds of livestock were depredated in all sites within the past ten years. 1623 sheep, 741 cattle, 639 goats, 193 donkeys, and 124 horses were predated. During the past ten years, $4.85 \pm 0.09$ sheep and 2.21 \pm 0.05 cattle were depredated per household. Approximately 2 goats were killed from each household $(1.91 \pm 0.02)$. The total number of killed livestock in the study area was 3320 . The mean number of all depredated livestock within the past ten years was $9.94 \pm 0.15$ per household. There was a significant difference among livestock depredated within past ten years $\left(X^{2}=432.2, P<0.001\right)$. The real difference was found when cattle and sheep were compared with other livestock $(P<0.05)$. Therefore, sheep were highly predated livestock and then cattle. Horse predation was the lowest (Table 2).

The past five years' depredation loss of livestock was also studied. All kinds of livestock were depredated in all sites within the past five years. Totally 970 sheep, 402 cattle, 361 goats, 91 donkeys, and 62 horses were predated. There was a significant difference in depredated livestock across kebeles $\left(\chi^{2}=303.6, P<\right.$ $0.001)$. Generally, $5.85 \pm 0.13$ livestock were depredated within the past five years per household.

Totally 199 sheep, 27 cattle, and 78 goats were killed. The predation of the three livestock was seemingly reduced last year in many villages, even though it does not mean that the general trend of predation is reduced. And there was an increasing rate in sheep and goat depredation. $1.15 \pm 0.02$ livestock was lost from each household. There was no reported predation of pack animals during 2018 GC.

There was a significant difference among respondents in their response to the trend of livestock depredation $\left(X^{2}=47.68, P<0.05\right)$. Almost half of $(49.01 \%)$ respondents mentioned the increasing trend of livestock predation. The trend was reported to be high within the Park (68\%). Nearly, $17 \%$ of respondents considered the trend as constant. Some of the respondents (14.34\%) believed livestock depredation is getting reduced. but no one was convinced in Rira that predation is reduced.

\section{The economic loss of households}


During the past ten years, households reported killings of 3320 livestock that cost 347,460.53 USD. Specifically, 1040.3 USD was lost from each household through livestock depredation (Table 4). Farming and small-scale trades are major sources of money for the majority of the respondents from which they earn an average of 31.57 USD per month. Loss of 8.66 USD per month constituted $27.45 \%$ of their monthly income which is expected to have a great sustenance impact.

Table 4 Total monetary loss of livestock predation in the study sites

\begin{tabular}{|llll|}
\hline $\begin{array}{l}\text { Target } \\
\text { livestock }\end{array}$ & $\begin{array}{l}\text { Approximate unit cost } \\
\text { (USD) }\end{array}$ & $\begin{array}{l}\text { Killed (within 10 } \\
\text { Years) }\end{array}$ & $\begin{array}{l}\text { Total monetary loss } \\
\text { (USD) }\end{array}$ \\
\hline sheep & 39.47 & 1623 & $64,065.79$ \\
\hline cattle & 263.16 & 741 & $195,000.00$ \\
\hline Goat & 52.63 & 639 & $33,631.58$ \\
donkey & 131.58 & 193 & $25,394.73$ \\
Hoarse & 236.84 & 124 & $29,368.42$ \\
\hline & Total & $\mathbf{3 3 2 0}$ & $\mathbf{3 4 7 , 4 6 0 . 5 2}$ \\
\hline
\end{tabular}

\section{Local predation-curbing techniques}

Different predator controlling methods were put into effect for several decades in the study area. Respondents mentioned six major mechanisms they used to control predators. These methods were watch-defend (95.21\%), pen construction (67.96\%), using dogs (59.28\%), direct kill (5.69\%), using poisoning (17.2\%), and destruction of predators' habitat (7.49\%) using fire (Table 5). Respondents (17.2\%) did use poisons to kill lions and leopards within the Park.

Table 5 Preventing mechanisms of predators used by local people in the study area (\%)

\begin{tabular}{|llllllll|}
\hline \multicolumn{1}{|c}{ Methods } & AT & WT & FA & WA & IS & Rira & Total \\
\hline Watch-defend & 20.95 & 16.77 & 13.17 & 13.17 & 19.16 & 11.98 & 95.21 \\
\hline Pen construction & 15.57 & 14.67 & 5.69 & 9.58 & 16.17 & 6.29 & $\mathbf{6 7 . 9 6}$ \\
\hline Using dogs & 10.78 & 14.67 & 5.69 & 6.89 & 16.17 & 5.09 & $\mathbf{5 9 . 2 8}$ \\
\hline Direct killing & 1.50 & 0.60 & 0.00 & 1.50 & 0.00 & 2.10 & $\mathbf{5 . 6 9}$ \\
\hline Poisoning & 0.00 & 0.00 & 0.00 & 0.00 & 0.00 & 17.2 & $\mathbf{1 7 . 2}$ \\
\hline Destruction of predators habitats & 0.00 & 0.00 & 1.20 & 0.00 & 0.00 & 6.29 & $\mathbf{7 . 4 9}$ \\
\hline
\end{tabular}

\section{Causes of livestock predation}


Indirect field observation was compared with the response of key informants and household to find the major causes of livestock predation in the study area. Human settlement (41\%), agricultural practices (38.6\%), overgrazing (25.3\%), deforestation for charcoal production (25.1\%), deliberate fire to free lands for agriculture (17.3\%) were noticed as major causes of livestock depredation. Many people living in and around the Park did not have to have their own private grazing land. Approximately, $28 \%$ of respondents are living within the Park and used it as a grazing field. According to the report of the Kebele administration, there was about 25,000 livestock within the Park up to October 2019 GC. A total of 874 ha field were used for agriculture in the central part of The Park. Many wild herbivores were noticed $(66.3 \%)$ to graze outside the Park boundary because of humans and their livestock activities within the Park. This situation favored predators to have double options; as predating livestock within the Park or follow natural preys out of the Park which may expose livestock living near and far from the Park for predation.

\section{Suggested mitigation strategies}

Different suggestions were given by key informants that are supposed to reduce predation: reduce predators' number, return them to the Park, compensation for inhabitants of the Park, awareness creation to know how to control predators, and no idea. The former four were what key informants expect the government (the Park management) to do. Some respondents $(5.69 \%)$ thought that the number of olive baboons and spotted hyena is outstandingly great. Majority of the key informants recommended that killing of problematic predators might reduce their effect. But $20 \%$ of Kls thought that returning them back to the Park is acceptable than killing wildlife. Many (39.2\%) of the respondents want to learn some techniques from the government to reduce livestock damage.

\section{Discussion}

The result of the present study revealed that there is a strong human-predator conflict in and around BMNP. However many respondents had a good attitude toward wildlife conservation, which did not correlate with their distance from the park $(P>0.05)$. Because without going to the Park they were able to interact with different wild animals found outside the Park. Having a good attitude towards wildlife conservation has not been a new phenomenon for many African countries. Many researchers conducted in Africa revealed that the majority of the local people have a good attitude towards wildlife conservation. $[15,16,30]$ noticed that many respondents had a positive attitude towards wildlife conservation in Zimbabwe, South Africa, and Namibia, respectively. As the present study showed, respondents who were highly attacked by predators had a negative attitude towards wildlife conservation. $(r=-0.64, P<0.05)$. According to the report of [35], the presence of a negative attitude about wildlife conservation among those who faced more attack from carnivores in Norwegian. A study conducted in Ethiopia [27] also found that respondents who confronted more attacks from carnivores had a negative attitude towards wildlife conservation. According to [13], the positive attitude of local people may be changed due to the high level of conflict. In the same manner, conflict mitigation methods are very important to keep local people's attitude positive. The positive attitude of coexisting people is very important for the conservation of carnivores' fauna and management efforts. Based on the evidence from several studies including the 
present, the author suggests that livestock predation conflict issues are important factors to determine the conservation attitude of local people which intern enervates the involvement of people in the conservation programs and activities.

Most (72.75\%) respondents agreed on the presence of livestock predation. All mentioned livestock predators were spotted hyena, olive baboon, common jackal, aardvark, genet, Ethiopian wolf, lion, and leopard. Common jackals, leopards, spotted hyenas and Ethiopian wolve were also found to be livestock predators in different parts of the country [29]. In another part of Africa baboons, lions, leopards, and hyenas were also mentioned among as major predators responsible for damage and killing of livestock [34]. One-third of respondents reported olive baboons and spotted hyenas as major livestock predators in the study area. Research concerning human-wildlife assessment in Malawi indicated baboons as crop raiders and predators [4]. One study [3] counted 704 livestock predation in the Web Valley of BMNP (19992002). According to this research, hyenas were responsible for $57 \%$ of the total livestock predated. Leopard was also made responsible for goats and sheep depredation in the previous study. A study conducted in the Menz Guassa district of Ethiopia [12] also reported the loss of sheep, goats, cattle, donkeys, and horses by common jackal, Ethiopian wolve, and hyenas with one additional predator in the Menz Guassa district of Ethiopia. In Kenya predators such as lion, leopard and hyena were found to be responsible for cattle, sheep, and goat losses [11]. Therefore, livestock predators are almost similar throughout the country and the continent.

There was no relationship between the number of livestock predators and distance from the Park $(r=-0.1$, $P=0.001$ ). This analysis showed that reported predators attack livestock not for local people are lived in or near the Park. There was a different conclusion given in some other related researches. According to [28] sheep loss to Ethiopian wolves was due to livestock approach to Ethiopian wolf habitat. Several wildlife species may have been comprised within some legal boundaries such as parks and protected areas. But the distribution of wildlife in Bale could be very different. However, BMNP harbors very important endemic species of the world such as Mountain nyala and Ethiopian wolf [43] many other animal species live outside the Park territories which make them to confront with human and their livestock.

There was an increasing trend of livestock depredation in the study area. The predation trend estimation across Kebeles did indicate an increasing rate. The number of predated livestock is expected to increase in the next decade. Almost half of (49.01\%) respondents stressed the increasing trend of livestock depredation. With the expectation of many depredation events, local people have been using six techniques for curbing the impact of carnivores' attack in the study area. Among all the techniques used, dogs rearing, direct killing, poisoning, and destruct habitats of predators can have a devastating impact on the wildlife of the Park. For instance, $17.2 \%$ of respondents live within the Park did use the poisonous substance to kill lions. This could affect the whole biodiversity through the food chain. The firing was also another mechanism performed by local people live inside protected areas to destruct the habitat of predators which chased away many wildlife populations including avian from the Park. This is supposed 
to be a major reason for more livestock depredation events Kebeles far from the Park. Alers et al. [2] and Vial [42] agreed that the causes of fire in BMNP are anthropogenic.

The present study identifies five root causes of livestock predation in and around the Park. Human settlement $(41 \%)$, agricultural practices $(38.6 \%)$, overgrazing $(25.3 \%)$, deforestation for charcoal production $(25.1 \%)$, and firing wildlife habitats $(17.3 \%)$ were found to be major causes of livestock depredation. During the study time, there was approximately 25,000 livestock that graze within the Park boundary. Furthermore, a total of 874 ha field was already occupied for agricultural purposes inside the Park. A study conducted in another part of the Park found that agricultural expansion, human settlement, overgrazing by livestock, deforestation, illegal grass collection, and poaching are Root causes of humanwildlife conflicts [36]. Another study from the Tsavo Conservation Area, Kenya, reported human settlement, Agricultural Expansion, deforestation, and poaching as the main causes of Human wildlife conflicts [21]. Also, life loss and injuries of humans and animals, crop and property damage, agricultural encroachment, developmental activities, and livestock grazing were reported as major reasons for human-wildlife conflict in different parts of Africa [17].

Finally, the results of the present study show that there is strong humans-livestock predator conflict in the study area. Therefore, the author suggested that conflict mitigation efforts focus on securing the livestock enclosure to protected areas [19]. Mitigation programs and strategies should be designed based on the positive interests of the local people. People live in and around protected areas suffer a great economic loss due to wildlife damage of livestock and crop. Hence they deserve to receive compensation for losses and ease the economic burden of predator conflict [31, 33] Ineffective compensation programs may actually increase the rate of wildlife killings $[31,33,40]$. Parallelly, the concerned government body should reduce human settlements, agricultural farmland expansions, and overgrazing in and around the BMNP.

\section{Conclusion}

Human-wildlife conflict has not been a new phenomenon for countries like Ethiopia where a high level of biological diversity coexists with humans in and around protected areas. Therefore, the findings of this study revealed mutual damage from both local people and predators. Hence, the foremost action should be awareness creation about the environmental, social, and economic importance of protected areas. Park management is also expected to promote community involvement. It is highly recommended to study the level of damage mainly outside the Park. Very quick action is recommended to be taken in appropriate space and time to reduce the long and short-term harm to both wildlife and human beings.

Some recommendations are given by the present study;

- Tourism plans should consider local people to be benefited from the income.

- Park management is expected to promote community involvement.

- Wildlife population study is highly recommended outside the Park. 
- There should be a buffer zone around the border to reduce conflict.

- Studding population status of olive baboon and spotted hyena.

- Regular compensation fee for farmers that face great damage from wildlife.

- Construct strong pens using stone than bamboo or any other soft material would reduce spotted hyena livestock predation.

- However it is hard to apply, redistribution of local people to other suitable territories would certainly reduced wildlife attacks.

- Pastoralist and farmers should enhance their carefulness to reduce livestock loss to some extent.

\section{Abbreviations}

a.s.I = above sea level; BMNP = Bale Mountains National Park; Kebeles (AT-Aloshe Tilo, WT-Waltai Tosha, WA-Waltai Azira, FA-Fassil Angesso and IS-Ititu Sura).

\section{Declarations}

\section{Ethics approval and consent to participate}

Permits for this research were issued by the Ethiopian Wildlife Conservation Authority (EWCA) and park management office. The "research ethics committee of Debre Markos University" has approved that verbal consent might be obtained from all participants. Written consent was not necessary since the required data is not such sensitive for respondents.

\section{Consent for publication}

Verbal consent

\section{Availability of data and materials}

The data used and analyzed during the current study is available from the corresponding author on a reasonable request, without disclosure of the interviewees.

\section{Competing interests}

The author declare no competing interests

\section{Funding}

No funding sources

\section{Author's contributions}


I am contributing for this work starting from designing the study and data collection up to data analysis and manuscript preparation. The author read and approved the final manuscript.

\section{Acknowledgements}

I am grateful for Bale Mountain National Park staff members for providing me with necessary information about the research and very important recent photographs. I would also like to be thankful for Salale University for providing suitable work conditions.

\section{Author's information}

Specialty - Ecology and Systematic Zoology

Current position at Salale University - Research and community Service Coordinator for College of Natural and computational Sciences

\section{References}

1. Alemneh A. Wildlife resources of Ethiopia: opportunities, challenges and future directions: from ecotourism perspective: a review paper. Natural Resources 2015;6:405-22.

2. Alers M, Bovarnick A, Boyle T, Mackinnon K, Sobrevila C. Reducing threats to protected areas, lessons from the field. UNDP: One UN Plaza; 2007.

3. Anagaw A, Williams S, Afework B, Thirgood S. Livestock predation in the Bale Mountains, Ethiopia. Afr J of Ecol. 2010;48:1076-82.

4. Anthony B. Wasambo J. Human-wildlife conflict study report. Vwaza Marsh Wildlife Reserve, Malawi; 2009.

5. Ethiopia: overview of selected biodiversity indicators. Addis Ababa: Biodiversity Indicators Development National Task Force; 2010.

6. Conover M. Resolving human-wildlife conflicts: the science of wildlife damage management. London, New York and Washington DC: A CRC Press Company, Boca Raton; 2002.

7. Cochran W. Sampling Techniques, 3rd ed. New York: John Wiley \& Sons; 1977.

8. Girma E, Jorgelina M, Sillero-Zubiri Ethiopian wolves conflict with pastoralists in small Afroalpine relicts. Afr J of Ecol. 2017;56:368-74.

9. Eldredge N. Life on earth: an encyclopedia of biodiversity, ecology, and evolution. USA, California: American Museum of Natural History; 2002.

10. Important bird areas of Ethiopia: a first inventory. Addis Ababa: Ethiopian Wildlife and Natural History Society; 1996.

11. Frank L, Woodroffe R, Ogada M. People and predators in Laikipia District, Kenya. In: Woodroffe R, Thirgood S, Rabinowitz A, editors. People and wildlife: conflict or coexistence. Cambridge: Cambridge University Press; 2005. p. 286-304. 
12. Getachew S. Habitat use and diet of golden jackal (Canis aureus) and human-carnivore conflict in Guassa community conservation area, Menz. (Unpublished MSc. Thesis). Addis Ababa: Addis Ababa University; 2010.

13. Hill C, Osborn F, Plumptre AJ. Human-wildlife conflict: identifying the problem and possible solutions. Albertine Rift Technical Report Series; 2002.

14. Hillman C. The Bale Mountains National Park area, southeast Ethiopia, and its management. Mount Res and Dev. 1988;8:253-58.

15. Infield M. Attitudes of a rural community towards conservation and a local conservation area in Natal, South Africa. Biol of Conserv. 1988;45:21-46.

16. Jones B, Barnes J. Human wildlife conflict study Namibian case study. Namibian: An Economic Analysis of HWC impacts in Caprivi; 2006.

17. Ladan SI. Examining human wild life conflict in Africa. In: International conference on biological, civil and environmental engineering; 2014. p. 102-5.

18. Lamarque F, Anderson J, Fergusson R, Lagrange M, Osei-Owusu Y, Bakker L. Human-wildlife conflict in Africa causes, consequences and management strategies. Rome: FAO forestry paper; 2009.

19. Lichtenfeld LL, Trout C, Kisimir EL. Evidence-based conservation: predator-proof bomas protect livestock and lions. Biodivers Conserv. 2015;24:483-91.

20. Linnell J, Swenson J, Andersen R. Predators and people: conservation of large carnivores is possible at high human densities if management policy is favorable. Anim Conserv. 2001;4:345-49.

21. Makindi SM, Mutinda MN, Olekaikai NK, Olelebo WL, Aboud AA. Human-wildlife conflicts: causes and mitigation measures in Tsavo conservation area, Kenya. Int J Sci Res. 2014;36:1025-31.

22. Marshall N. The key informant techniques. Fam Pract. 1996;13:92-97.

23. Matsaketsa G, Muboko N, Gandiwa E, Kombora DM, Chibememe G. An assessment of humanwildlife conflicts in local communities bordering the western part of Save Valley Conservancy, Zimbabwe. Glob Ecol Conserv. 2019;20:e00737

24. Matseketsa G, Mukamuri BB, Muboko N, Gandiwa E. An assessment of local people's support to private wildlife conservation: a case of save valley conservation and fringe communities, Zimbabwe. Scientifica 2019; Article ID 2534614, 11 pages.

25. Mc Guinness S, Taylor D. Farmers' perceptions and action to decrease crop raiding by forest-dwelling primates around a Rwandan forest fragment. Hum Dimens Wildl. 2014;19:179-190.

26. Melaku T. Wildlife in Ethiopia: endemic large mammals. Wor $\mathrm{J}$ of Zoo. 2011;6:108-16.

27. Mesele Y. Human-wildlife (Gelada Baboon and Ethiopian Wolf) conflict in and around the Simien Mountains National Park. M.Sc. Thesis. Addis Ababa: Addis Ababa University; 2006.

28. Mesele Y, Afework B, Zelealem T. Human-gelada baboon conflict in and around the Simien Mountains National Park, Ethiopia. Afr J of Ecol. 2008;47:276-282.

29. Mesele Y, Afework B, Zelealem T. Human-Ethiopian wolf Conflict in and around the Simien Mountains National Park, Ethiopia. Inter J of Ecol and Environ Sci. 2009;34:149-55. 
30. Mhlanga L. Conflict between wildlife and people in Kariba town, Zimbabwe. Zambezia 2001;1:1-14.

31. Naughton-Treves L, Grossberg R, Treves A. Paying for tolerance: rural citizens' attitudes toward wolf depredation and compensation. Conserv Biol. 2003;17:1500-11.

32. Newmark WD, Manyanza DN, Gamassa DM, Sariko HI. The Conflict between Wildlife and Local People Living Adjacent to Protected Areas in Tanzania: Human Density as a Predictor. Conserv Biol. 1994;8:249-55.

33. Nyhus PJ, Osofsky SA, Ferraro P, Madden F, Fischer H. Bearing the cost of human-wildlife conflict: the challenges of compensation schemes. In: Woodroffe R, Thirgood S, Rabinowitz AR, editors. People and wildlife conflict or coexistence? Cambridge: Cambridge University Press; 2005. p. 107-21.

34. Ogada O, Ogada L. Factors influencing levels of carnivore-livestock conflicts in Samburu Heartland and proposed mitigation measures. Unpublished consultancy report to African Wildlife; 2004.

35. Roskaft E, Händel B, Bjerke T, Kaltenborn B. Human attitudes towards large carnivores in Norway. Wild Biol. 2007;13:172-85.

36. Sefi M. Coexistence between human and wildlife: the nature, causes and mitigations of human wildlife conflict around Bale Mountains National Park, Southeast Ethiopia. BMC Ecol. 2020;20:51.

37. Smith R, Kasiki S. A spatial analysis of human-elephant conflict in Tsavo ecosystem, Kenya. Switzerland: A report to the African elephant specialist group, human-elephant conflict task force, IUCN; 2000.

38. Sogbohossou E, De longh H, Sinsin B, De Snoo G, Funston J. Human-Predator Conflicts Around Pendjari Biosphere Reserve Northern Benin. Human-carnivore conflicts part Il; 2011.

39. Temesgen G. Threats of Bale Mountains National Park and solutions, Ethiopia. J of Phys Sci and Environ Stud. 2015;2:10-16.

40. Treves A, Jurewicz RL, Naughton-Treves L. Wilcove DS. The price of tolerance: wolf damage payments after recovery. Biodivers Conserv. 2009;18:4003-21.

41. Treves A, Karanth KU. Human-Carnivore Conflict and Perspectives of Carnivore Management Worldwide. Conserv Biol. 2003;17:1491-99.

42. Vial F. Conservation science for common ground: developing the necessary tools to manage livestock grazing pressure in Bale Mountains National Park, Ethiopia. PhD dissertation. Scotland:University of Glasgow; 2010.

43. Vreugdenhil D, Vreugdenhil A, Tamirat T, Anteneh S, Zelealem T. Gap Analysis of the Protected Areas System of Ethiopia. USA: World Institute for Conservation and Environment; 2012.

44. Watson C, Milner-Gulland E, Mourato S. Direct consumptive use value of ecosystem goods and services in the Bale Mountains Eco-region, Ethiopia. In: Randall D, Thirgood, D, Kinahan A, editors. Walia-special edition on the Bale Mountain. Mozambique, Maputo; 2011. p. 189-204.

45. White PCL, Jennings NV, Renwick AR, Baker NHL. Questionnaire in ecology: a review of past use and recommendations for best practice. J Apple Ecol. 2005;42:421-430. 
46. Woodroffe R, Frank G. Lethal control of African Lions (Panthera leo): local and regional population impacts. Anim Conserv. 2005;8:91-99.

47. Woodroffe R, Thirgood S, Rabinowitz A. People and wildlife: conflict or coexistence. Cambridge: Cambridge University Press; 2005.

48. Yalden D. The extent of high ground in Ethiopia compared to the rest of Africa. Sinet Ethio J of Sci. 1983;6:35-39.

49. Yalden D, Largen M. The endemic mammals of Ethiopia. Mam Rev. 1992;22:115-150.

\section{Additional Files}

The following items are not available with this version:

\section{Questionnaires}

The data gathering questionnaires were developed after critical and detail review previously conducted similar researches. The file is uploaded as supplementary file.

\section{Photographs (Observation)}

In this file, photographs of injured and killed livestock are included. Furthermore local communities have been expanding their activities in different forms. Some of the activities were captured and included in the file to evidence the results of the present study. Additional photographs that were obtained from the park's administration database are also included.

\section{Figures}

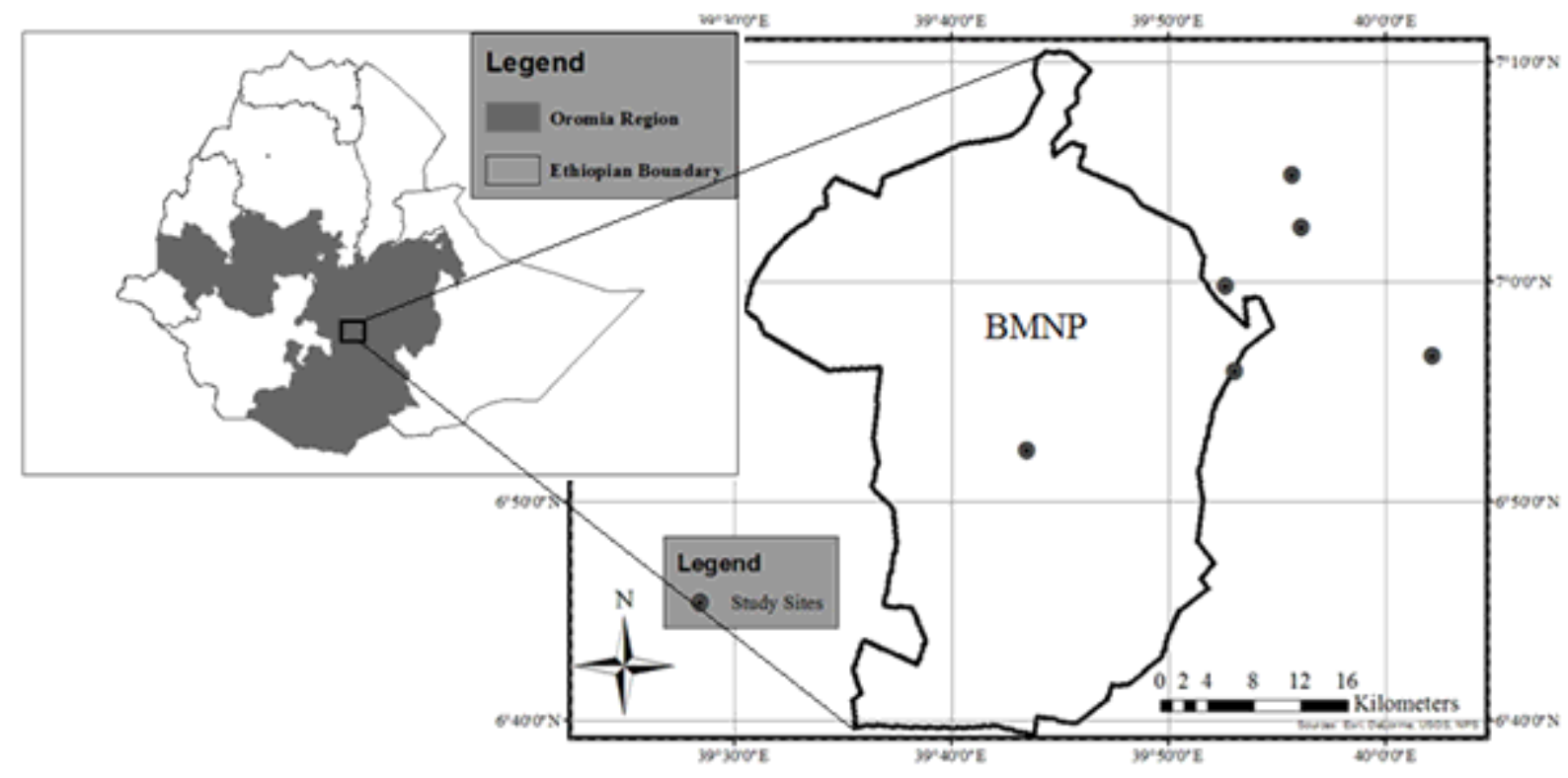

Figure 1 
Map of the study area and sample sites (Israel Sebsibe, 2020) Note: The designations employed and the presentation of the material on this map do not imply the expression of any opinion whatsoever on the part of Research Square concerning the legal status of any country, territory, city or area or of its authorities, or concerning the delimitation of its frontiers or boundaries. This map has been provided by the authors.

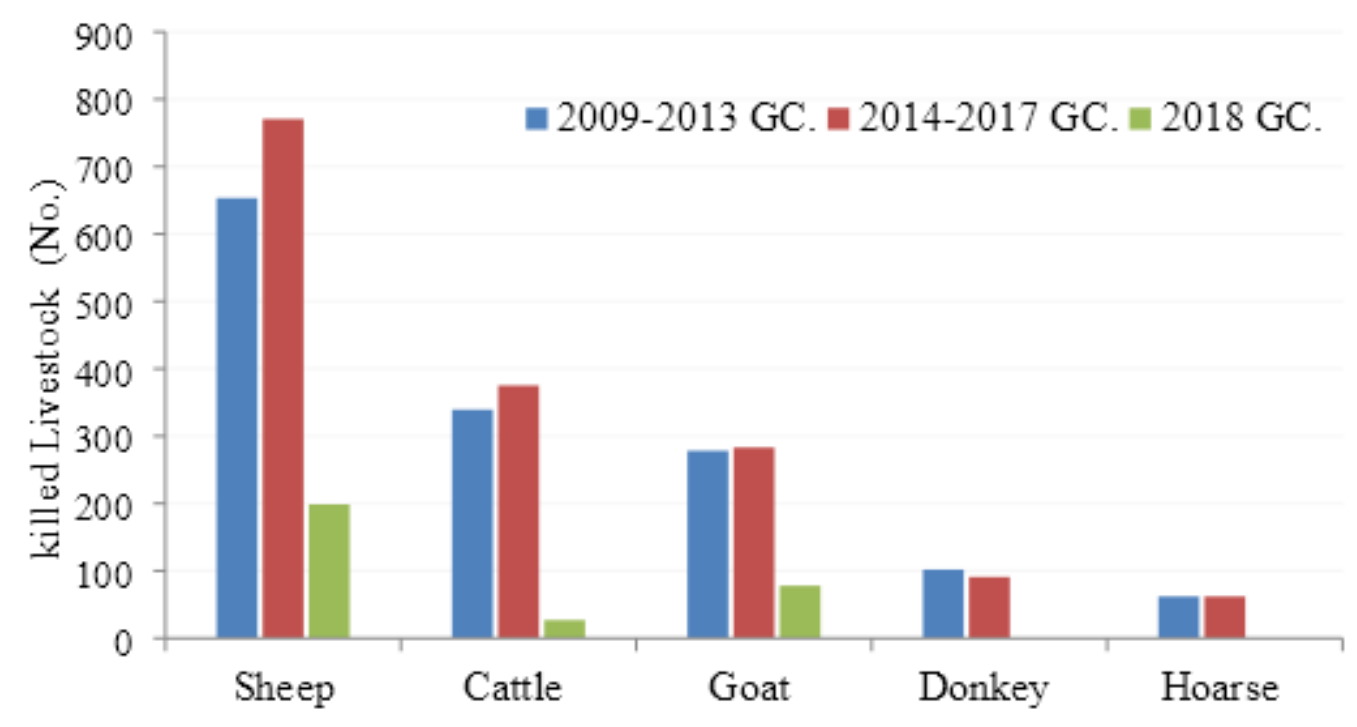

Figure 2

Trend of livestock damage during 2009-2018 GC.

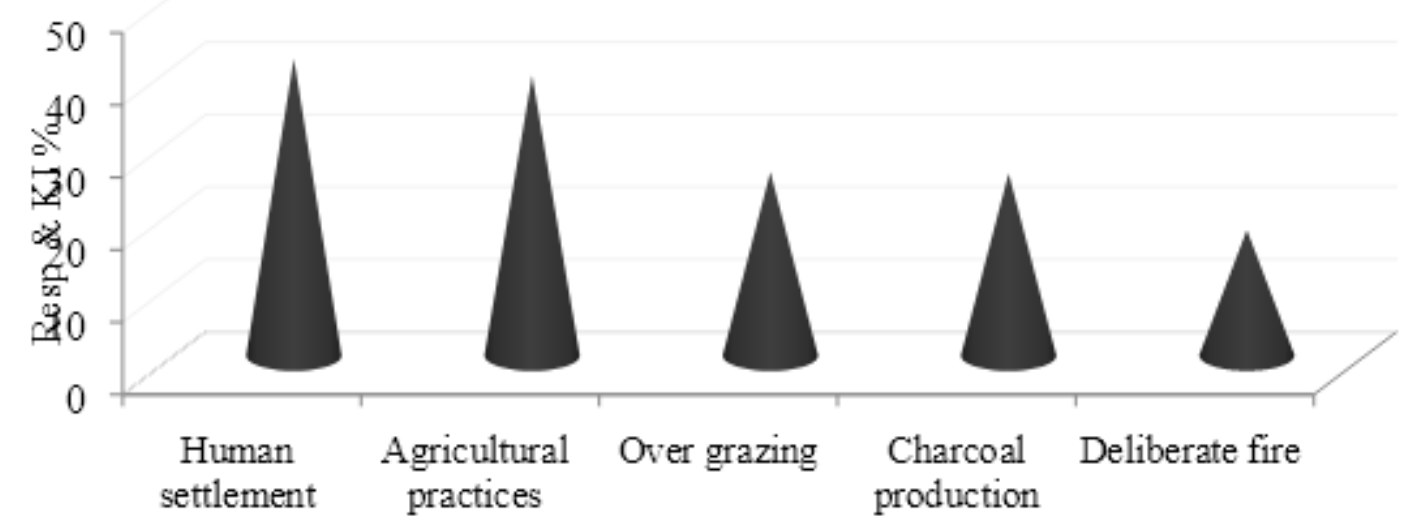

Resp \& KI = Respondents and Key informants

Figure 3

Major causes of livestock predation in the study area 